\title{
Reg3 $\alpha$ Overexpression Protects Pancreatic $\beta$ Cells from Cytokine-Induced Damage and Improves Islet Transplant Outcome
}

\author{
Ying Ding, ${ }^{1,2}$ Yuemei Xu, ${ }^{2}$ Xuanyu Shuai, ${ }^{2}$ Xuhui Shi, ${ }^{2}$ Xiang Chen, ${ }^{3}$ Wenbin Huang, ${ }^{4}$ Yun Liu, ${ }^{5}$ \\ Xiubin Liang, ${ }^{5}$ Zhihong Zhang, ${ }^{1}$ and Dongming Su, ${ }^{2,3,5}$ \\ ${ }^{1}$ Department of Pathology, the First Affiliated Hospital of Nanjing Medical University, Nanjing, China; ${ }^{2}$ Department of Pathology, \\ Nanjing Medical University, Nanjing, China; ${ }^{3}$ Center of Cellular Therapy, the Second Affiliated Hospital of Nanjing Medical \\ University, Nanjing, China; ${ }^{4}$ Department of Pathology, Nanjing First Hospital, Nanjing, China; and ${ }^{5}$ Center of Metabolic Research, \\ Nanjing Medical University, Nanjing, China
}

\begin{abstract}
The process of islet transplantation for treating type 1 diabetes has been limited by the high level of graft failure. This may be overcome by locally delivering trophic factors to enhance engraftment. Regenerating islet-derived protein $3 \alpha$ (Reg3 $\alpha$ ) is a pancreatic secretory protein which functions as an antimicrobial peptide in control of inflammation and cell proliferation. In this study, to investigate whether Reg3 $\alpha$ could improve islet engraftment, a marginal mass of syngeneic islets pretransduced with adenoviruses expressing Reg3 $\alpha$ or control EGFP were transplanted under the renal capsule of streptozotocin-induced diabetic mice. Mice receiving islets with elevated Reg3 $\alpha$ production exhibited significantly lower blood glucose levels $(9.057 \pm 0.59 \mathrm{mmol} / \mathrm{L}$ versus $13.48 \pm 0.35 \mathrm{mmol} / \mathrm{L}, P<0.05)$ and improved glucose-stimulated insulin secretion $(1.80 \pm 0.17 \mathrm{ng} / \mathrm{mL}$ versus $1.16 \pm 0.16 \mathrm{ng} / \mathrm{mL}$, $P<0.05)$ compared with the control group. The decline of apoptotic events $(0.57 \% \pm 0.15 \%$ versus $1.06 \% \pm 0.07 \%, P<0.05)$ and increased $\beta$-cell proliferation $(0.70 \% \pm 0.10 \%$ versus $0.36 \% \pm 0.14 \%, P<0.05)$ were confirmed in islet grafts overexpressing Reg3 $\alpha$ by morphometric analysis. Further experiments showed that Reg3 $\alpha$ production dramatically protected cultured islets and pancreatic $\beta$ cells from cytokine-induced apoptosis and the impairment of glucose-stimulated insulin secretion. Moreover, exposure to cytokines led to the activation of MAPKs in pancreatic $\beta$ cells, which was reversed by Reg $3 \alpha$ overexpression in contrast to control group. These results strongly suggest that Reg $3 \alpha$ could enhance islet engraftments through its cytoprotective effect and advance the therapeutic efficacy of islet transplantation.
\end{abstract}

Online address: http://www.molmed.org

doi: $10.2119 / \mathrm{molmed} .2014 .00104$

\section{INTRODUCTION}

Type 1 diabetes is characterized by a gradual loss of $\beta$-cell mass and function. In recent years, islet transplantation has become a promising therapeutic approach for type 1 diabetic patients (1). Long-term insulin independence requires large quantities of islet infusions. However, chronic loss of islet grafts is still an unsolved hurdle for clinical islet transplantation $(2,3)$. Vulnerable islets are susceptible to the injuries caused by the hypoxia, various immunological damages, the extent of islet revascularization and other factors, which lead to poor engraftment after the procedure $(3,4)$. Several studies reported that inflammatory cytokines, including IL- $1 \beta$, TNF- $\alpha$ and
Address correspondence to Dongming Su, Department of Pathology, Nanjing Medical University, 140 Hanzhong Road, Nanjing 210029, China. Phone: +86-25-86862085; Fax: +8625-86862085; Email: sudongming2014@163.com.

Submitted May 15, 2014; Accepted for publication December 16, 2014; Epub (www.molmed.org) ahead of print December 17, 2014.

\section{The Feinstein Institute for Medical Research Empowering Imagination. Pioneering Discovery.}

IFN $-\gamma$ released in the aforementioned pathological processes may account for the graft loss and dysfunction in islet transplantation $(5,6)$. Therefore, more effective control of cytokine-induced damage to islet engraftment for achieving prolonged maintenance of islet grafts has been suggested.

Regenerating gene (Reg) family proteins (REGs) were first identified as secretory proteins in the pancreatic juice of rats with induced acute pancreatitis (7), and have been proven to be a multifunctional factor involved in cell proliferation or differentiation (8). Although the members of this family contain a similar C-type lectin-like domain in the sequence, the suggested function of the various REGs are startlingly diverse (8). As one Reg family protein, regenerating 
islet-derived protein $3 \alpha(\operatorname{Reg} 3 \alpha)$, also named hepatocarcinoma-intestinepancreas/pancreatitis-associated protein (HIP/PAP), has been found to affect biological activities in multiple organs (9-11). In the pancreas, $\operatorname{Reg} 3 \alpha$ has been observed to express in the acinar epithelium and in non $\beta$ cells in islets $(12,13)$, which has been shown to protect pancreatic acinar cells both in vitro (14) and in vivo (15). Meanwhile, growing evidence links Reg3 $\alpha$ and other Reg proteins to the regeneration of not only exocrine but also of the endocrine tissue of the pancreas (8). Increased Reg $3 \alpha$ expression also was detected in the cadaver islets with type 2 diabetic individuals (16) and islets from pregnant rats, both processes associated with elevated islet mass (17), indicating that Reg $3 \alpha$ may influence islet regeneration and $\beta$-cell proliferation.

Therefore, with respect to the potential impact of Reg $3 \alpha$ on pancreatic islets and the fact that Reg $3 \alpha$ plays an important role in tissue regeneration and inflammation, we hypothesized that elevated Reg $3 \alpha$ production locally in islet grafts would protect islets from inflammatory cytokine-induced apoptosis, contribute to improved preservation of islet mass and better glycemic control in transplants. To elucidate the effect of Reg $3 \alpha$ on islet survival and function during transplantation, a mouse model of syngeneic marginal islet mass transplantation was used in this study. Further investigation of the possible underlying mechanisms also was carried out in cultured islets and a murine pancreatic $\beta$-cell line INS-1.

\section{MATERIALS AND METHODS}

\section{Vector}

The plasmid vector pcDNA3.1-Reg3 $\alpha$ derived by inserting mouse $\operatorname{Reg} 3 \alpha$ cDNA (GenBank NM_011259) into the Eco RI and Kpn I restriction sites of pcDNA3.1 (Invitrogen [Thermo Fisher Scientific, Waltham, MA, USA]) was a kind gift from Jun-Li Liu of Montreal Diabetes Research Centre at Canada. Adenovirus rAd-mReg3 $\alpha$ was obtained commercially from Yingrun Biotechnologies Inc.
(Changsha, Hunan, China). The shuttle plasmid pYr-adshuttle-4 containing two expression cassettes for mouse $\operatorname{Reg} 3 \alpha$ and EGFP fluorescence gene with a titer of $1 \times$ $10^{10}$ plaque-forming units $(\mathrm{pfu}) / \mathrm{mL}$ was constructed, each gene independently expressed. The rAd-EGFP vector expressing EGFP fluorescence gene with a titer of $1 \times$ $10^{10} \mathrm{pfu} / \mathrm{mL}$ was used as control.

\section{Animal Studies}

Adult male Sprague Dawley rats (Slac, Shanghai, China) were induced with diabetes using bolus streptozotocin (SigmaAldrich, St Louis, MO, USA) treatment with a single dose of $70 \mathrm{mg} / \mathrm{kg}$ as described previously $(3,18)$. With nonfasting blood glucose concentrations measuring greater than $16.7 \mathrm{mmol} / \mathrm{L}$ for three consecutive days, these rats were killed for pancreas morphometric analysis.

Male eight-week-old inbred BALB/c mice (Slac) were used in this experiment as donors and recipients. Diabetes was induced by intraperitoneal injections of streptozotocin (Sigma-Aldrich) at one dose of $200 \mathrm{mg} / \mathrm{kg}$ as described previously $(3,18)$. With nonfasting blood glucose concentrations measuring greater than $16.7 \mathrm{mmol} / \mathrm{L}$ for three consecutive days, these mice were randomly assigned to three groups for transplantation. Islets were isolated and cultured using a previously described procedure (18). Aliquots of islets $(n=150)$ were mock treated with PBS buffer or incubated with Reg3 $\alpha$ or EGFP vector at a defined multiplicity of infection (MOI, $100 \mathrm{pfu} / \mathrm{cell}, 1000$ cell/islet) at $37^{\circ} \mathrm{C}, 5 \% \mathrm{CO}_{2}$ for $16 \mathrm{~h}$, followed by transplantation under the renal capsule (Reg3 $\alpha, \mathrm{n}=11$; EGFP, $\mathrm{n}=9$; mock, $\mathrm{n}=7$ ) using the established procedure $(3,18)$. After transplantation, the food intake and body weight were recorded. Blood glucose was monitored randomly every five days using AccuChek (Roche, Mannheim, Germany). At $30 \mathrm{~d}$ after transplantation, nephrectomy was performed. The blood glucose levels were recorded for another $3 \mathrm{~d}$.

Animals were maintained in a 12-h light-dark cycle at a temperature of $23^{\circ} \mathrm{C}$ with free access to water and regular chow diet. All animal experiments were carried out in accordance with the Guide for the Care and Use of Laboratory Animals (19) and permitted by the Institutional Animal Care and Usage Committee of Nanjing Medical University.

\section{Intraperitoneal Glucose Tolerance Test (IPGTT) and Glucose-Stimulated Insulin Release}

Mice were fasted for $6 \mathrm{~h}$ and intraperitoneally injected with $3 \mathrm{~g} / \mathrm{kg}$ body weight of glucose. Blood glucose levels were measured at $0,15,30,60,120$ min after glucose loaded. Area under curve (AUC) of IPGTT was calculated to compare the differences among each group. During IPGTT, aliquots $(20 \mu \mathrm{L})$ of blood samples before and $30 \mathrm{~min}$ after glucose infusion were collected from tail vein, and serum insulin levels were measured by mouse insulin ELISA kit (Millipore, Darmstadt, Germany) following its protocol.

\section{Morphometric Analysis}

Harvested rat pancreata were fixed and embedded for immunostaining. Paraffin sections were immunostained with rabbit anti-glucagon (1:100, SAB4501137; Sigma-Aldrich) or goat anti$\operatorname{Reg} 3 \alpha$ (1:100, sc-50969; Santa Cruz Biotechnology, Santa Cruz, CA, USA) primary antibodies.

After nephrectomy under nonfasting conditions, pancreatic islet graft-bearing kidneys were fixed and embedded for immunohistochemistry and immunofluorescence as described previously $(20,21)$. For morphology analysis, hematoxylin and eosin (H\&E) staining was used. Paraffin sections were also immunostained with rabbit anti-insulin (1:100, 4590S; Cell Signaling Technology, Danvers, MA, USA) or goat anti-Ki-67 (1:100, sc-7846; Santa Cruz) primary antibodies. $\beta$-cell apoptosis in islet grafts was confirmed by the terminal deoxynucleotidyl transferase dUTP nick end labeling (TUNEL) assay with an in situ death detection kit (Roche). The pancreatic $\beta$-cell proliferative and apoptotic ratio in grafts were calculated as the number of Ki-67/insulin or TUNEL/ insulin double-staining cells divided by 
the number of insulin-positive cells in the insulin-positive region of interest, respectively. For vessel analysis, insulin/lectin (1:50, FL-1201, Vector Laboratories Inc., Burlington, Ontario, Canada) double staining was used to visualize blood vessels in interested areas. The vessel density was calculated as described in legends.

For TUNEL staining of cultured islets, aliquots of isolated mouse islets $(n=50)$ either mock treated with PBS or transduced with $\operatorname{Reg} 3 \alpha$ or EGFP vector for $16 \mathrm{~h}$ were incubated in the presence or absence of the inflammatory cytokine cocktail (5 ng/mL human IL- $\beta, 30 \mathrm{ng} / \mathrm{mL}$ TNF- $\alpha$, and $30 \mathrm{ng} / \mathrm{mL}$ IFN- $\gamma$; R\&D Systems, Abingdon, UK) for $24 \mathrm{~h}$. Cytokineinduced islet cell apoptosis was confirmed by the TUNEL assay as mentioned above. The apoptotic ratio was calculated as the number of TUNEL-positive staining nuclei adjusted for areas in each islet.

In each morphological analysis, three nonconsecutive sections were viewed under microscope (DP70, Olympus, Tokyo, Japan) or confocal microscope (FV1000, Olympus).

\section{Glucose-Stimulated Insulin Secretion (GSIS)}

Isolated mouse islets either mock treated with PBS or transduced with Reg3 $\alpha$ or EGFP vector were plated in 24-well plates (10 islets per well). Apoptosis was induced by cytokine cocktail ( $5 \mathrm{ng} / \mathrm{mL}$ human IL- $\beta$, $30 \mathrm{ng} / \mathrm{mL}$ TNF- $\alpha$ and $30 \mathrm{ng} / \mathrm{mL}$ IFN- $\gamma$ ) treatment for $24 \mathrm{~h}$. After being preincubated in glucose-free Krebs-Ringer bicarbonate (KRB), the islets were treated with KRB containing $5 \mathrm{mmol} / \mathrm{L}$ glucose for $1 \mathrm{~h}$, and followed for another $1 \mathrm{~h}$ in the presence of $25 \mathrm{mmol} / \mathrm{L}$ glucose KRB. The insulin concentrations in collected supernatants were measured by ELISA kit as mentioned above.

\section{Cell Culture, Cell Viability and Reactive Oxygen Species (ROS) Detection}

Rat insulin-secreting cell line INS-1 (passage 15-30) was cultured as described previously (22). The pcDNA3.1$\operatorname{Reg} 3 \alpha$ and control pcDNA3.1 vectors were transfected using X-tremeGENE transfection reagents (Roche Diagnostics) according to the manufacturer's instructions. The expression of Reg $3 \alpha$ was determined in both culture media and cell lysate to confirm the efficacy of transfection. After $24 \mathrm{~h}$, INS-1 cells were incubated in the presence or absence of cytokine cocktail as mentioned above for another $24 \mathrm{~h}$. Then the cell viability was determined by the MTT reduction conversion assay, Annexin V/PI staining and flow cytometry analysis as described previously $(23,24)$. The ROS generation was detected using commercial kits (Beyotime, Shanghai, China) following the protocol as described previously (25).

\section{Western Blotting}

After different treatments, the proteins in the conditioned media and lysate of isolated islets and INS-1 cells were subjected to SDS-PAGE and blotted onto PVDF membranes. The proteins were probed with primary antibodies against Reg3 $\alpha$ (1:500, AF3907; R\&D), caspase-3 (1:1000, 9665S; Cell Signaling Technology), Bcl-2 (1:1000, 2876S; Cell Signaling Technology), PCNA (1:1000, BS1289; Bioworld Technology Inc. St. Louis Park, MN, USA), p27KIP1 (1:500, SAB4500068; Sigma-Aldrich), Pdx-1 (1:2000, ab47267; Abcam, Cambridge, UK), MafA (1:800, sc27140; Santa Cruz), phosphorylated Thr202/Tyr204-p44/42 MAPK (Erk1/2) (1:1000, BS5016; Bioworld) and total p44/42 MAPK (Erk1/2) (1:1000, BS3627; Bioworld), phosphorylated Thr180/ Tyr182-p38 MAPK (1:1000, 9211S; Cell Signaling Technology) and total p38 MAPK (1:1000, 9212S; Cell Signaling Technology), phosphorylated Thr183/Tyr185JNK (1:1000, BS4322; Bioworld) and total JNK (1:1000, AP0370; Bioworld), GAPDH (1:5000, AP0063; Bioworld) and tubulin (1:10000, PA1-41331; Thermo Fisher Scientific), followed by incubation with HRPconjugated secondary antibodies for analyze as described previously (26).

\section{Statistics}

Data are expressed as mean \pm SEM. Comparisons between two groups were assessed by Student $t$ test, or one-way ANOVA, then Tukey multiple-comparison posttest was performed for statistical analysis of multiple groups. $P$ values $<0.05$ were considered statistically significant.

All supplementary materials are available online at www.molmed.org.

\section{RESULTS}

\section{Reg3 $\alpha$ Production in Islet Grafts Improved Syngeneic Islet Engraftment in Streptozotocin-Induced Diabetic Mice}

Before transplantation, initial experiments prepared and characterized the rAd-mReg3 $\alpha$ vector (Supplemental Figures $1 \mathrm{~A}-\mathrm{D})$. There was no significant change in food intake and body weight within each group (Supplemental Figure 2A) $30 \mathrm{~d}$ after transplantation. After $30 \mathrm{~d}$, although a rapid decrease of blood glucose was observed in all recipients after islet transplantation, diabetic mice transplanted with $\operatorname{Reg} 3 \alpha$-transduced islets had lower random blood glucose (RBG) levels $(9.057 \pm 0.59 \mathrm{mmol} / \mathrm{L})$ in comparison with that in diabetic mice receiving the same number of islets pretransduced with EGFP vector (13.48 \pm $0.35 \mathrm{mmol} / \mathrm{L}$ ) or mock-treated islets $(13.43 \pm 2.01 \mathrm{mmol} / \mathrm{L}$, Figure 1A). No detectable differences were found in RBG levels between EGFP and the mock group (see Figure 1A). To investigate the glucose disposal rates in different groups, a glucose tolerance test was performed at d 15 and 30 after transplantation. At 15 d after transplantation, a similar pattern was observed in diabetic mice receiving $\operatorname{Reg} 3 \alpha$-transduced islets, which showed significantly improved blood glucose profiles compared with EGFP or mock group at $15 \mathrm{~min}(21.29 \pm 2.93 \mathrm{mmol} / \mathrm{L}$ versus $23.43 \pm 1.25 \mathrm{mmol} / \mathrm{L}$ or $23.25 \pm$ $1.28 \mathrm{mmol} / \mathrm{L}$, respectively; $P<0.05)$ and $30 \mathrm{~min}(19.80 \pm 3.10 \mathrm{mmol} / \mathrm{L}$ versus $23.18 \pm 1.88 \mathrm{mmol} / \mathrm{L}$ or $23.83 \pm$ $0.93 \mathrm{mmol} / \mathrm{L}$, respectively; $P<0.05$ ) after glucose challenge. There was a $30.8 \%$ reduction of AUC in Reg $3 \alpha$ group versus EGFP group and a $30.1 \%$ reduction ver- 
A

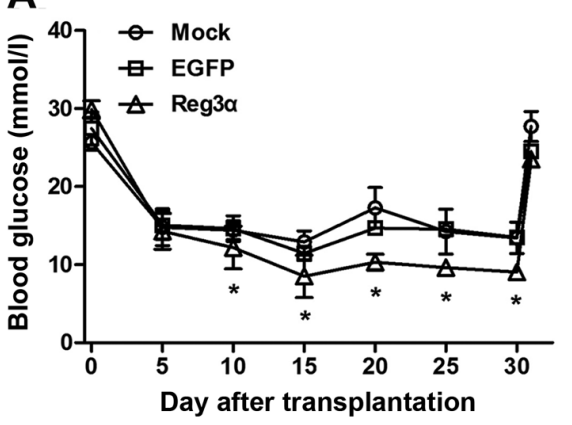

C

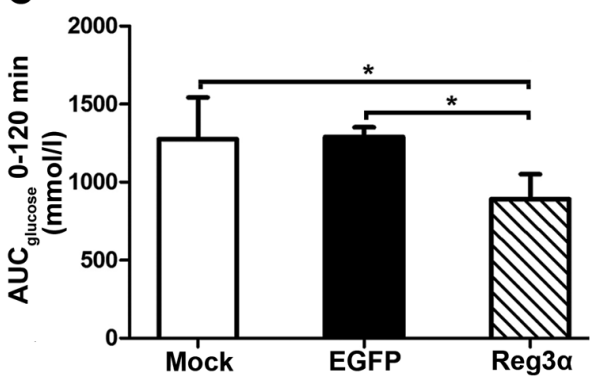

$\mathbf{B}$

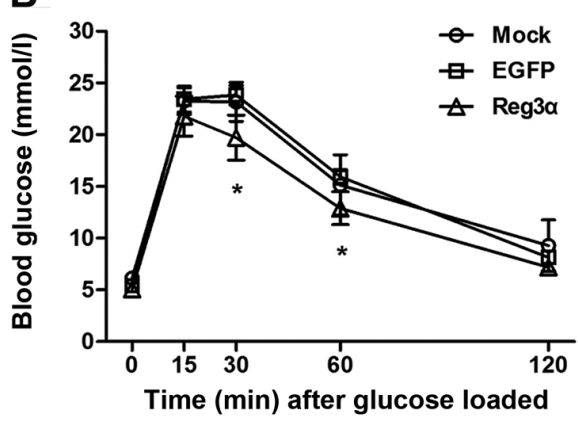

D

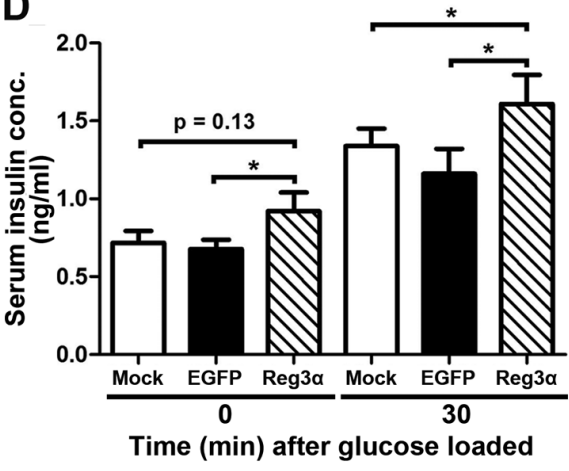

Figure 1. Reg3 $\alpha$ overexpression in islet grafts improved glycemic control in streptozotocininduced diabetic mice. (A) Random blood glucose levels in diabetic mice receiving Reg3 $\alpha$-transduced islets (Reg3 $\alpha, n=11$ ) or EGFP vector-transduced islets (EGFP, $n=9$ ), and mock-treated mice (Mock, $n=7$ ) groups were measured after transplantation. (B) IPGT was performed at $15 \mathrm{~d}$ after transplantation. Blood glucose levels were measured after glucose loading at indicated time. (C) Area under curve (AUC) of IPGT was calculated to compare the differences among each group. (D) During IPGTT, serum insulin levels were determined before and $30 \mathrm{~min}$ after glucose infusion. Values represent the means \pm SEM, ${ }^{\star} P<0.05$ denoted significance between Reg3 $\alpha$ group and EGFP or Mock group.

sus mock group (Figures 1B, C). Similar results of IPGTT were shown at $\mathrm{d} 30$ after transplantation (Supplemental Figures $2 \mathrm{~B}, \mathrm{C}$ ).

Accordingly, we found that diabetic mice receiving $\operatorname{Reg} 3 \alpha$-transduced islets had relatively higher plasma insulin levels $(0.92 \pm 0.12 \mathrm{ng} / \mathrm{mL}$ versus $0.67 \pm$ $0.06 \mathrm{ng} / \mathrm{mL}$ in the EGFP group, $P<0.05$; versus $0.72 \pm 0.08 \mathrm{ng} / \mathrm{mL}$ in the mock group, $P=0.13$, Figure 1D) under fasting conditions. Furthermore, $30 \mathrm{~min}$ after glucose $(3 \mathrm{~g} / \mathrm{kg})$ was administrated to the mice, glucose-stimulated plasma insulin levels were increased significantly in $\operatorname{Reg} 3 \alpha$-transduced mice in comparison with control EGFP vector and mocktreated group $(1.80 \pm 0.17 \mathrm{ng} / \mathrm{mL}$ versus $1.16 \pm 0.16 \mathrm{ng} / \mathrm{mL}$ in EGFP group, $P<$
0.05 ; versus $1.26 \pm 0.10 \mathrm{ng} / \mathrm{mL}$ in mock group, $P<0.05$, see Figure 1D). Similar results also were observed at d 30 after transplantation (Supplemental Figure 2D). The effect of Reg $3 \alpha$ production on islet grafts also was illustrated with morphometric analysis. The retrieved graftbearing kidneys were embedded and sectioned followed by H\&E staining and immunohistochemical staining using an insulin antibody. There were no obvious differences in morphology of grafts among each group $30 \mathrm{~d}$ after transplantation, but optical density of insulin staining in Reg3 $\alpha$ group was increased significantly compared with EGFP or mock group (Figures 2A, D).

At $30 \mathrm{~d}$ after transplantation, an immediate recurrence of severe hyperglycemia could be detected in all diabetic mice after removing the islet grafts by unilateral nephrectomy. No significant differences in blood glucose levels were detected among $\operatorname{Reg} 3 \alpha$, EGFP and mock group (see Figure 1A), suggesting that islet grafts were the major responsible factors for the glycemic control in all recipients.

\section{Reg $3 \alpha$ Production in Islet Grafts Preserved Functional Islet Mass by Influencing $\beta$-Cell Apoptosis and Replication}

TUNEL assay and Ki-67 immunofluorescence staining were performed to detect $\beta$-cell apoptosis and replication rates in grafts, respectively. The apoptotic rate was reduced by about $50 \%$ in $\operatorname{Reg} 3 \alpha$ group versus EGFP or mock group $(0.57 \% \pm 0.15 \%$ in $\operatorname{Reg} 3 \alpha, 1.06 \% \pm 0.07 \%$ in EGFP, $P<0.05 ; 1.16 \% \pm 0.11 \%$ mock group, $P<0.05$, Figures $2 \mathrm{~B}, \mathrm{E})$, while $\beta$-cell replication in Reg $3 \alpha$ group was almost two-fold higher than EGFP group $(0.70 \% \pm 0.10 \%$ in $\operatorname{Reg} 3 \alpha, 0.36 \% \pm 0.14 \%$ in EGFP group, $P<0.05 ; 0.45 \% \pm 0.06$ in mock group, $P=0.07$, Figures $2 \mathrm{C}, \mathrm{F}$ ).

\section{Reg $3 \alpha$ Production Protected Primary Cultured Islets from Cytokine-Induced Damage}

Islets pretransduced by Reg $3 \alpha$ or control EGFP vector or receiving mock treatment were incubated in the presence/ absence of the inflammatory cytokine cocktail (IL- $\beta$, TNF- $\alpha$ and IFN- $\gamma$ ) for $24 \mathrm{~h}$, five- to six-fold of apoptotic cells could be observed in cytokine-treated islets compared with normal cultured islets (5.36 \pm 0.84-fold in cytokine-treated mock group, Figures 3A, B). However, TUNEL staining showed that there were lower numbers of apoptotic cells in $\operatorname{Reg} 3 \alpha$-transduced islets than in control EGFP-transduced islets and normal cultured islets under cytokine stimulation (3.42 \pm 0.58 -fold in Reg3 $\alpha$ transduced, $6.84 \pm 1.10-$ fold in EGFP group, $P<0.05 ; 5.36 \pm 0.84$-fold in mock group, $P<0.05$, see Figures $3 \mathrm{~A}, \mathrm{~B})$.

Afterward, measurement of GSIS in primary cultured mouse islets after $24 \mathrm{~h}$ cytokine (IL-1 $\beta$ ) treatment revealed that although cytokine-injured insulin secretion 
A

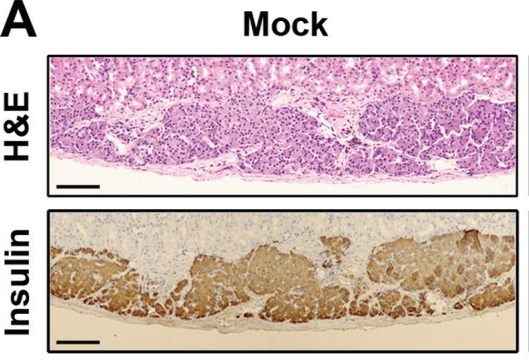

B Insulin TUNEL

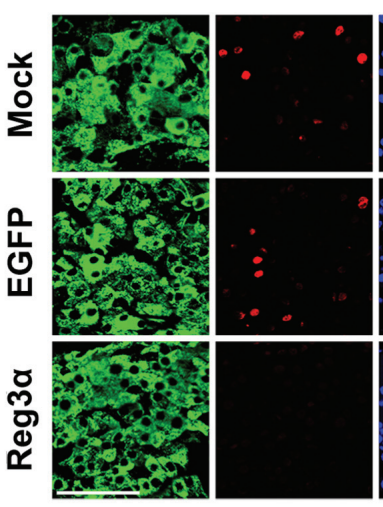

D
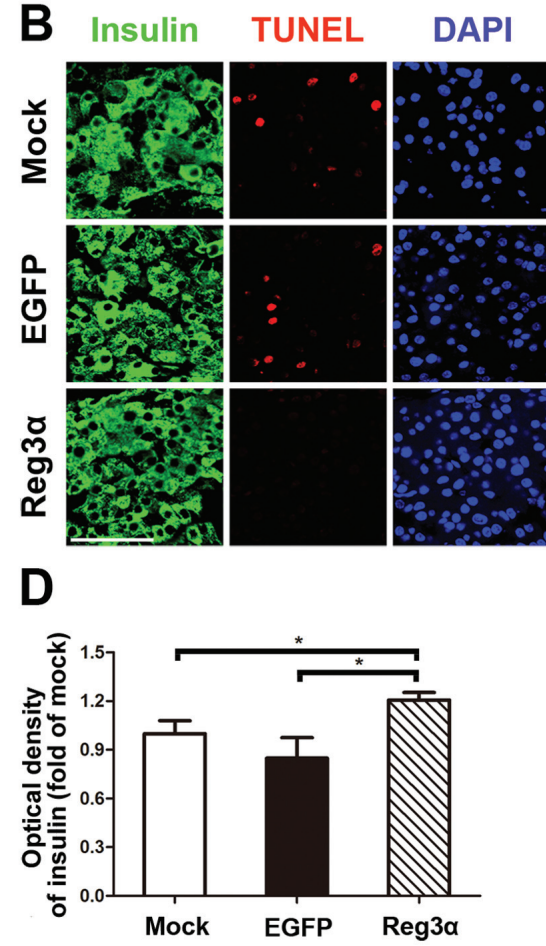

EGFP
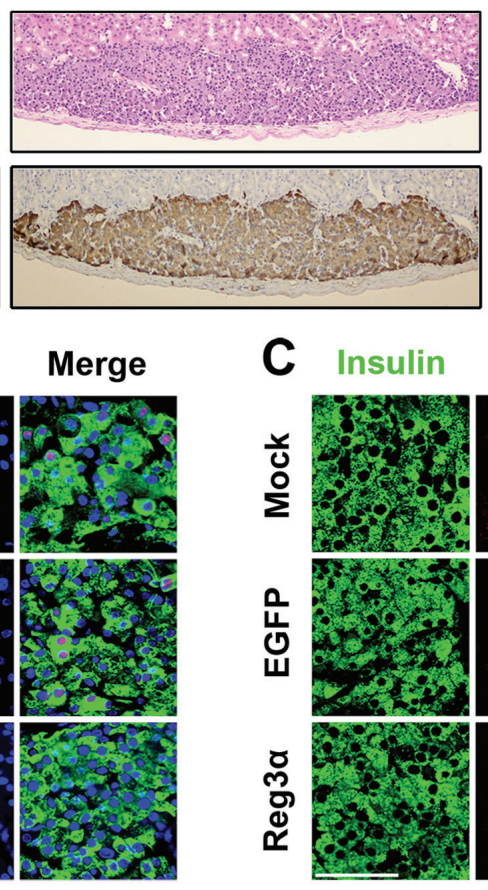

E

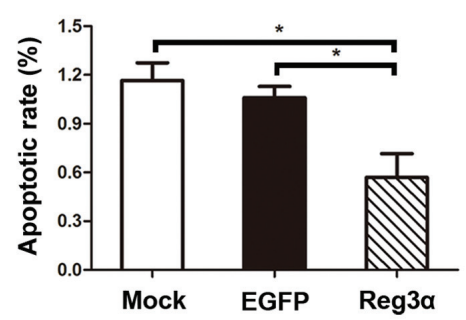

$\operatorname{Reg} 3 \alpha$
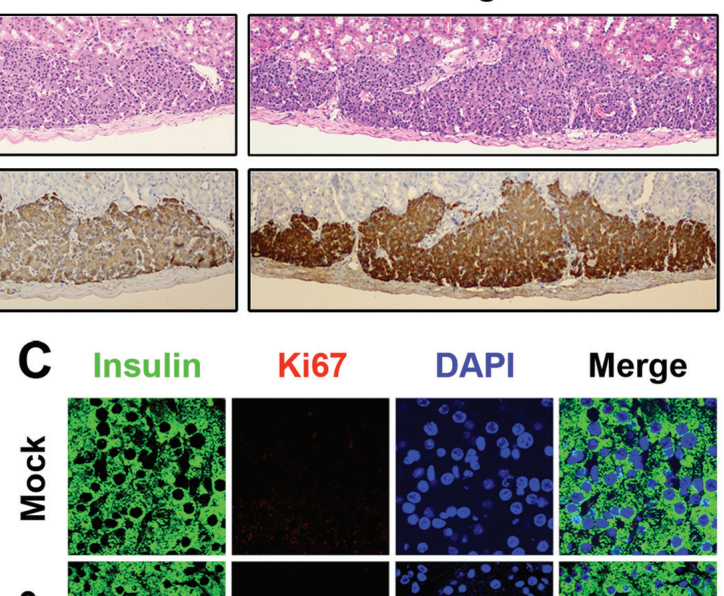

Merge

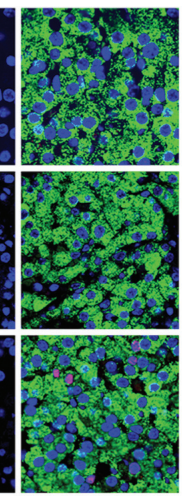

$\mathbf{F}$

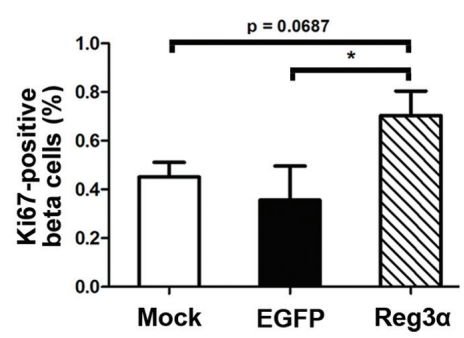

Figure 2. Reg3 $\alpha$ overexpression in islet grafts preserved functional islet mass by influencing $\beta$-cell apoptosis and replication. (A) Functioning islet grafts under the renal capsule of diabetic BALB/c mice were retrieved on d 30 after transplantation. H\&E staining and immunohistochemical staining of insulin using 3,3'-diaminobenzidine tetrahydrochloride (DAB) were analyzed. Scale bar $=100 \mu \mathrm{m}$ and referred to all panels. (B) Apoptotic and (C) replicating $\beta$ cells were stained with TUNEL and Ki-67 conjugated with red fluorescence in islet grafts, respectively. Insulin showed green and nuclei were stained with blue DAPI dye. Scale bar = $50 \mu \mathrm{m}$ and referred to all panels. (D) Insulin staining was analyzed semiquantitatively by the average optical density of insulin ${ }^{+}$cells adjusted for islet areas. (E-F) The apoptotic (E) and proliferative (F) ratio of pancreatic $\beta$ cells in grafts was calculated as averaging the number of $\mathrm{TUNEL}^{+} / \mathrm{insulin}^{+}$or $\mathrm{Ki}-67^{+} / \mathrm{insulin}^{+}$cells divided by the number of insulin ${ }^{+}$cells in islet grafts, respectively. At least three sections from animals were analyzed in each treatment group. Values represent the means \pm SEM, ${ }^{*} P<0.05$ denoted significance between Reg3 $\alpha(n=11)$ and EGFP $(n=9)$ or Mock $(n=7)$ group.

was decreased compared with normal cultured islets $(2.78 \pm 0.16 \mathrm{ng}$ and $5.23 \pm$ $0.33 \mathrm{ng}$, respectively, $P<0.05)$, Reg $3 \alpha$ production significantly restored cytokineinduced impairment of GSIS in response to $25 \mathrm{mmol} / \mathrm{L}$ glucose stimulation (4.64 \pm $1.05 \mathrm{ng}$ in $\operatorname{Reg} 3 \alpha, 2.78 \pm 0.16 \mathrm{ng}$ in EGFP group, $P<0.05 ; 2.78 \pm 0.2 \mathrm{ng}$ in mock group, $P<0.05$, Figure $3 C$ ). Interestingly, without cytokine treatment, Reg $3 \alpha$ produc- tion also helped to increase GSIS compared with control and EGFP vector-treated islets, although the differences did not quite achieve significance (see Figure 3C).

\section{Reg3 $\alpha$ Production Attenuated Pancreatic $\beta$-Cell Injury Induced by Cytokines}

Plasmid vector pcDNA3.1-Reg3 $\alpha$ and control vector were prepared and used in this experiment to overexpress $\operatorname{Reg} 3 \alpha$ in the INS-1 cell line (Supplemental Figure $1 \mathrm{E})$. To investigate whether $\operatorname{Reg} 3 \alpha$ production had a similar protective effect on insulin-secreting cell lines such as primary cultured islets, cell viability of INS-1 cells with different treatments was measured by MTT assay. Reg3 $\alpha$ production could restore cytokineinduced impairment significantly in cell 
A
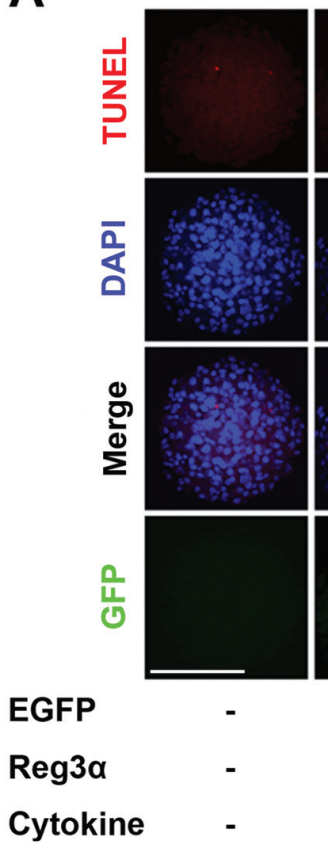

B

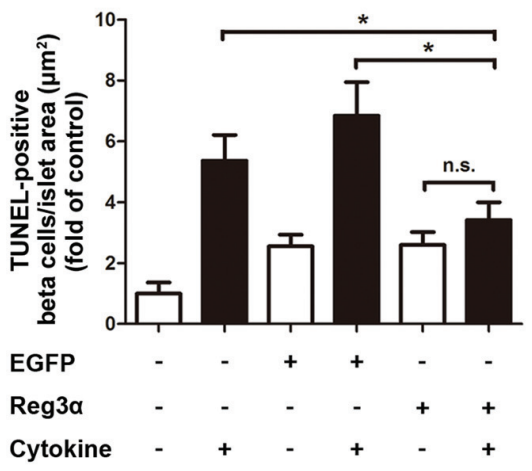

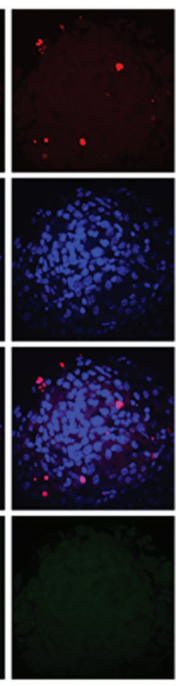

$-$

$-$

$+$
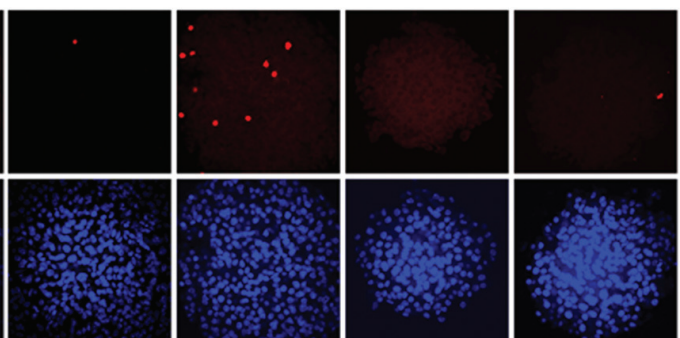

.
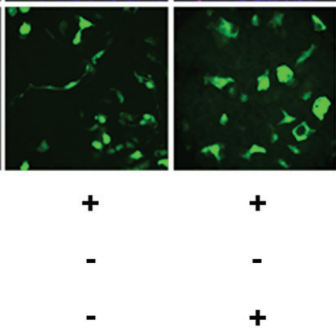

ค ค
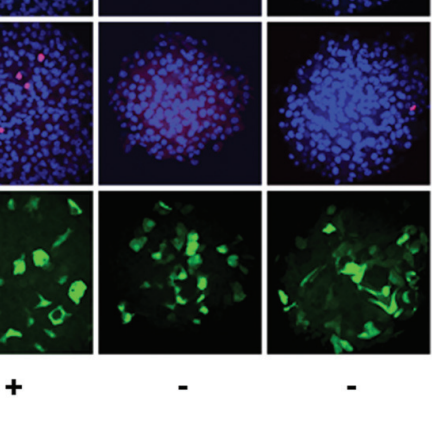

$-$
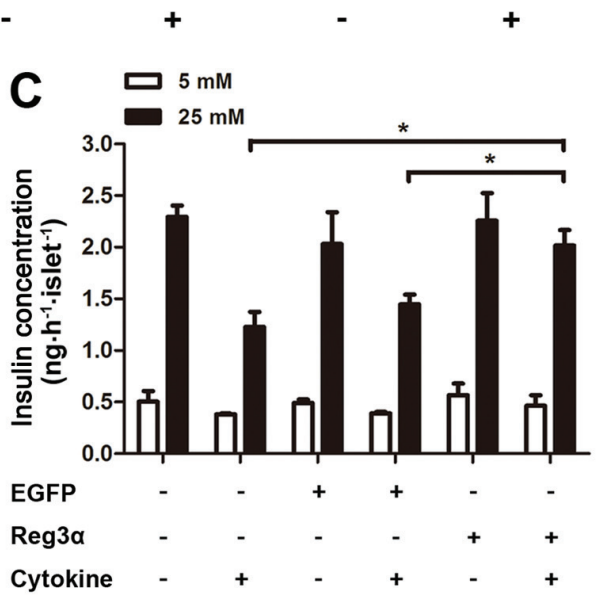

Figure 3. Reg3 $\alpha$ overexpression protected primary cultured islets from cytokine-induced damage. (A) Cytokine-induced islet cell apoptosis was determined by TUNEL staining. TUNEL-positive cells showed red fluorescence in nuclei, and all nuclei in each islet were marked with DAPI (blue). The transduction efficiency also was observed by green fluorescent protein (GFP) gene under the fluorescence microscope. Scale bar, $100 \mu \mathrm{m}$ (refers to all panel-A subpanels). (B) The apoptotic ratio of islet cells was calculated as the number of TUNEL-positive nuclei adjusted for islet area. At least 10 islets were analyzed in each group. (C) Insulin secretion under stimulation of glucose $(5 \mathrm{mmol} / \mathrm{L}$ and $25 \mathrm{mmol} / \mathrm{L}$, respectively) was measured in each group. Values represent the means $\pm S E M, n=3$. * $P<$ 0.05 denoted significance; n.s. was not significant.

viability compared with pcDNA3.1transfected INS- 1 cells $(0.5 \pm 0.03$ and $0.31 \pm 0.03$, respectively, $P<0.05$, Figure $4 \mathrm{~A})$. Interestingly, in the absence of cytokines, Reg $3 \alpha$ production also increased cell viability slightly compared with pcDNA3.1-transfected and normal INS-1 cells (see Figure 4A). Furthermore, Annexin V/PI staining and flow cytometry analysis were performed. The early apoptotic cells were identified by direct visualization of the green fluorescence- labeled Annexin V staining and the red fluorescence-labeled PI staining was performed simultaneously to distinguish between the late apoptotic and necrotic cells. Results showed that Reg $3 \alpha$ production in INS-1 cells decreased significantly in both early and late apoptotic cell numbers compared with the pcDNA3.1-transfected group (Figure 4B). Similar results were found by the flow cytometry analysis $(10.51 \% \pm 2.73 \%$ versus $29.01 \% \pm 3.73 \%, P<0.01$, Figures $4 C, D)$. And there were no obvious differences in cytokine-induced apoptosis between pcDNA3.1-Reg3 $\alpha$ and the negative vector-transfected group (see Figure $4 \mathrm{D})$. Elevated levels of cleaved caspase-3 were obviously found in cytokine-stimulated INS-1 cells (Figures 5A, D). However, Reg $3 \alpha$ production suppressed the deleterious effect of cytokines obviously (see Figures 5A, D). Bcl-2 protein levels also were determined. Higher expression levels of Bcl-2 were found in the pcDNA3.1-Reg3 $\alpha$-transfected group in comparison with pcDNA3.1-transfected group under cytokine stimulation (Figures $5 \mathrm{~A}, \mathrm{C}$ ).

In addition to the amelioration of $\beta$-cell apoptosis, the impact of Reg $3 \alpha$ on $\beta$-cell proliferation also was studied. It was found that after $24 \mathrm{~h}$ treatment with cytokines, the expression levels of PCNA (proliferation cell nuclear antigen) and a key transcriptional activator related to $\beta$-cell proliferation called Pdx-1 (pancreatic and duodenal homeobox 1) were reduced, while the p27Kip1 (cyclin-dependent kinase inhibitor 1B) protein levels were obviously increased (Figures 5B, F-H). However, Reg $3 \alpha$ production in INS-1 cells could observably restore these cytokine-induced detrimental effects (see Figures 5B, F-H).

Moreover, we detected the expression levels of MafA (v-maf avian musculoaponeurotic fibrosarcoma oncogene homolog A), a key transcriptional activator related to insulin biosynthesis. Reg $3 \alpha$ production restored cytokine-induced decreases in MafA expression levels in INS-1 cells (Figures 5B, E). 
A
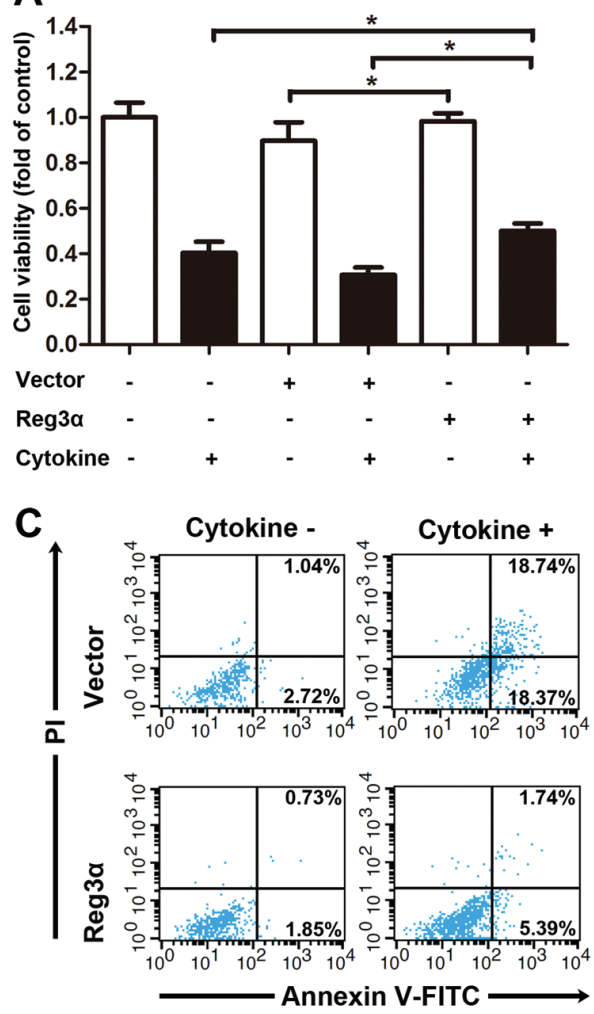

B

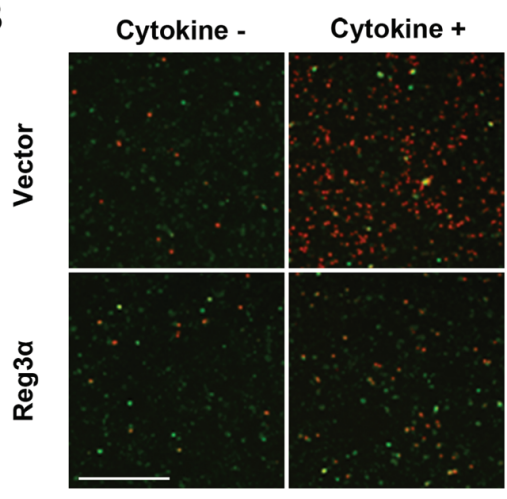

D

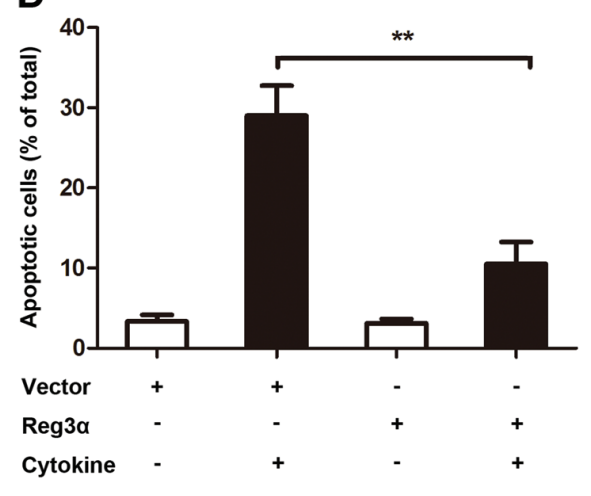

Figure 4. Reg $3 \alpha$ overexpression attenuated pancreatic $\beta$-cell injury induced by cytokines. (A) Vector or Reg $3 \alpha$-transfected cells and normal cultured cells were incubated in the presence or absence of the inflammatory cytokine cocktail for $24 \mathrm{~h}$, cell viability was measured by MTT assay. (B) Direct visualization of Annexin V/PI staining was imaged by a microscope. Annexin $V$ showed green fluorescence while PI showed red. Scale bar, $150 \mu \mathrm{m}$ (refers to all panel-B subpanels). (C) Cytokine-induced apoptosis were analyzed by flow cytometry. (D) FCM results were summarized as apoptosis rates. Values represent the means $\pm \mathrm{SEM}, \mathrm{n}=3 .{ }^{*} P<0.05,{ }^{* *} P<0.01$ denoted significance.

\section{Reg3 $\alpha$ Production Suppressed Cytokine-Induced Activation of p38 MAPK and ERK Phosphorylation}

To define the probable mechanisms contributing to the protective effect of $\operatorname{Reg} 3 \alpha$ production on cytokine-induced apoptosis and dysfunction, cytokine-activated $\beta$-cellspecific mitogen-activated protein kinase (MAPKs) was examined. The p38 mitogenactivated protein kinase (MAPK) and an extracellular signal-regulated kinase (ERK) phosphorylation were increased obviously after cytokine treatment in INS-1 cells (Figure 6). However, p38 MAPK phosphorylation was reversed in Reg $3 \alpha-$ overexpressed cells under cytokine treatment (Figures 6A-C). Meanwhile, Reg3 $\alpha$ production also showed inhibitory effects on ERK phosphorylation (Figures 6D-F). However, Reg $3 \alpha$ production seems to have no consistent impact on cytokineactivated c-Jun $\mathrm{NH}_{2}$-terminal kinase (JNK) phosphorylation (data not shown). In addition, $\operatorname{Reg} 3 \alpha$ production had no significant effect on MAPKs pathway in the absence of cytokines (see Figure 6).

\section{DISCUSSION}

As increasingly diverse functions of Reg3 $\alpha$ were reported (9-11), we refined the investigation to focus on the expression and localization of Reg $3 \alpha$ immunoreactivity in the murine diabetic pancreas (Supplemental Figure 3). Reg3 $\alpha$ previously was considered as expressing in non- $\beta$-cells of NOD islets and the acinar epithelium (27-29). We further showed that $\operatorname{Reg} 3 \alpha$ expression was restricted mainly to pancreatic $\alpha$ cells of streptozotocin-induced diabetic models, the colocalization of Reg $3 \alpha$ and glucagon immunoreactivity was predominant. This report proves Reg3 $\alpha$ has a well conserved expression in diabetic islets among different species which could imply a potential role for this protein in impaired islet turnover. Whether Reg $3 \alpha$ immunoreactivity represents a precursor endocrine cell remains a focus of our current investigation. Additionally, compared with the low expression level in normal islets, islet Reg3 $\alpha$-immunoreactive cells were upregulated significantly after streptozotocin treatment, indicating its strong induction of islet protection/regeneration in response to stress/damage. Increased expression of Reg $3 \alpha$ in diabetic islets may have been a consequence of direct toxicity of hyperglycemia, since $\operatorname{Reg} 3 \alpha$ was identified as a glucose metabolism-related gene in the pancreas for the glucose-dependent preservation of $\beta$-cell function (30).

During the early posttransplant period, islets are susceptible to damage exerted by inflammatory cytokines IL- $1 \beta$, TNF- $\alpha$ and IFN- $\gamma$, which results in the survival and subsequent engraftment of only a fraction of transplanted islets $(<30 \%$ transplanted cell mass) (1,31). Syngeneic islet transplantation in streptozotocininduced diabetic recipient mice, a model representing early host nonspecific immune responses including exposure to inflammatory cytokines $(18,32,33)$, allowed us to focus the effects of Reg $3 \alpha$ production on transplant outcome. Local production or pretreatment with trophic factors in islet graft may provide an ideal window to protect against cytokine-mediated dysfunction and subsequent improvement in islet function (18). In this research, we attempted to abrogate the detrimental effect of inflammatory cytokines by elevating Reg3 $\alpha$ production locally in syngeneic islet grafts. It was shown that diabetic mice receiving a marginal islet mass pretransduced by $\operatorname{Reg} 3 \alpha$ vector displayed better glycemic control and glucose-stimulated insulin secretion 
A

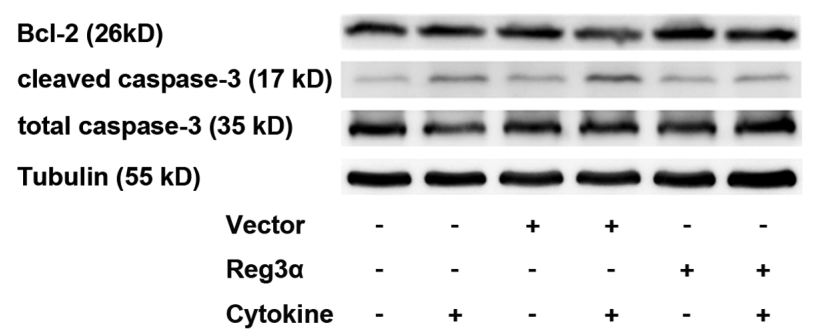

B

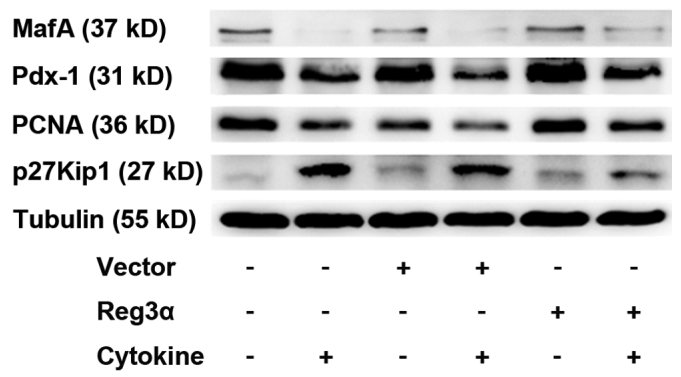

E MafA

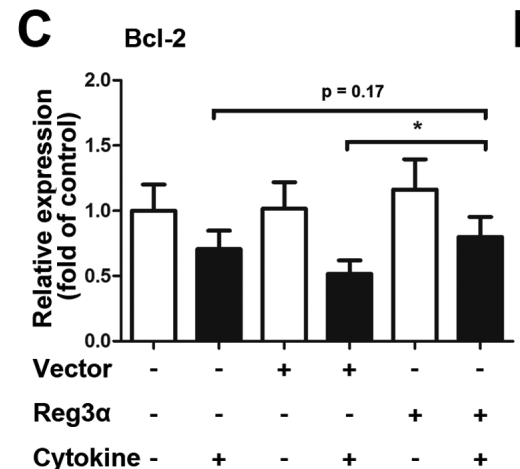

D cleaved caspase-3
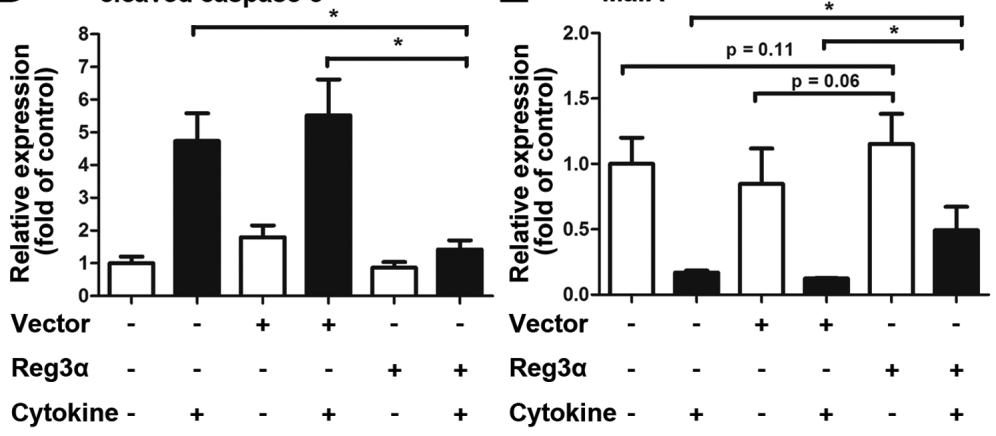

$\mathbf{F}$

G PCNA

H p27Kip1
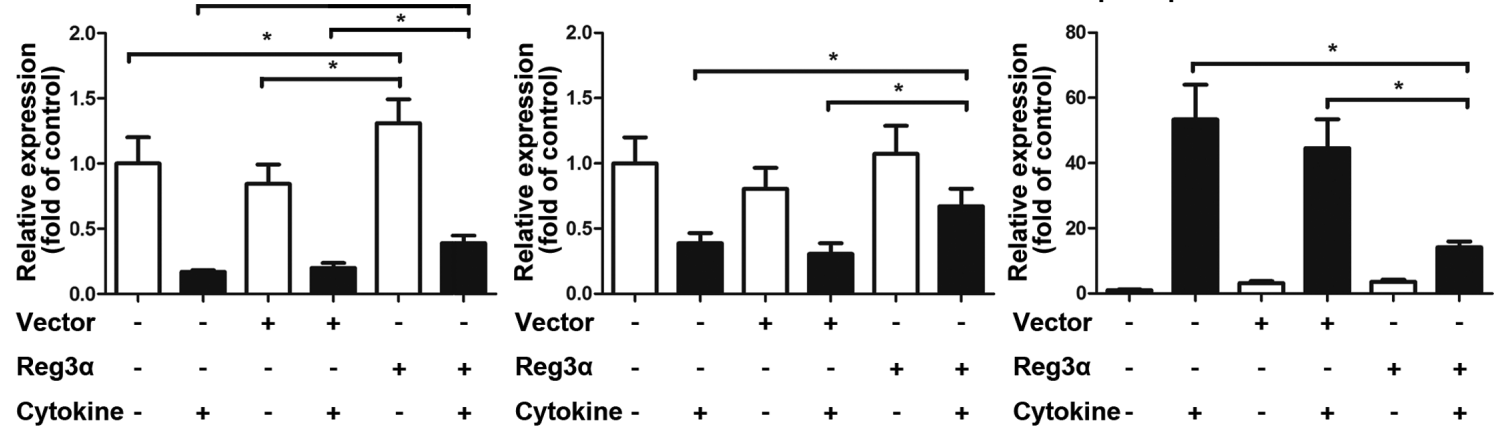

Figure 5. Western blotting analysis of Reg3 $\alpha$ effect on INS-1 cells viability and function. (A) After different treatment, Western blotting of $\mathrm{BCl}-2$, cleaved caspase-3 and total caspase-3 expression was showed and adjusted for tubulin expression. (B) Western blotting of Pdx-1, MafA, PCNA and P27Kipl expression was performed. Tubulin was used as a loading control. A representative blot was presented from three independent experiments. $(\mathrm{C}-\mathrm{H})$ The ratio of interest protein to loading control was shown. Values represent the means $\pm \mathrm{SEM}, \mathrm{n}=3$. ${ }^{*} P<0.05$ denoted significance.

compared with the control group. The mechanism by which Reg $3 \alpha$ may produce this beneficial effect appeared to be related to a decrease in $\beta$-cell apoptosis, coupled with an increase in $\beta$-cell replication from the morphological analyses of the islet grafts. Furthermore, these findings were in keeping with in vitro studies that showed the deleterious effect of cytokines on islet viability and function was significantly mitigated in cytokine-treated islets with elevated Reg3 $\alpha$ production.
We performed nephrectomy of the graftbearing kidney at $30 \mathrm{~d}$ after transplantation, which showed in a recurrence of hyperglycemia in different groups. Thus, although $\operatorname{Reg} 3 \alpha$ gene was reported to induce human pancreatic ductal tissue into insulin-producing cells and to improve glycemic control in streptozotocininduced diabetic mice (34), the better glycemic control in Reg3 $\alpha$ overexpressed grafts could be due to the functional islet transplants rather than to $\beta$-cell regenera- tion in the pancreas of streptozotocin-induced diabetic mice. As opposed to the $\operatorname{Reg} 3 \alpha$ group, the control group maintained hyperglycemia along with lower amplitudes of glucose-stimulated insulin release, correlating with reduced intragraft insulin-positive cells. Indeed, Reg $3 \alpha$ has been shown to promote the proliferation of different cell types $(11,34,35)$. It would be of interest to determine the potential capability of Reg3 $\alpha$ on islet graft revascularization, as the rate and extent 

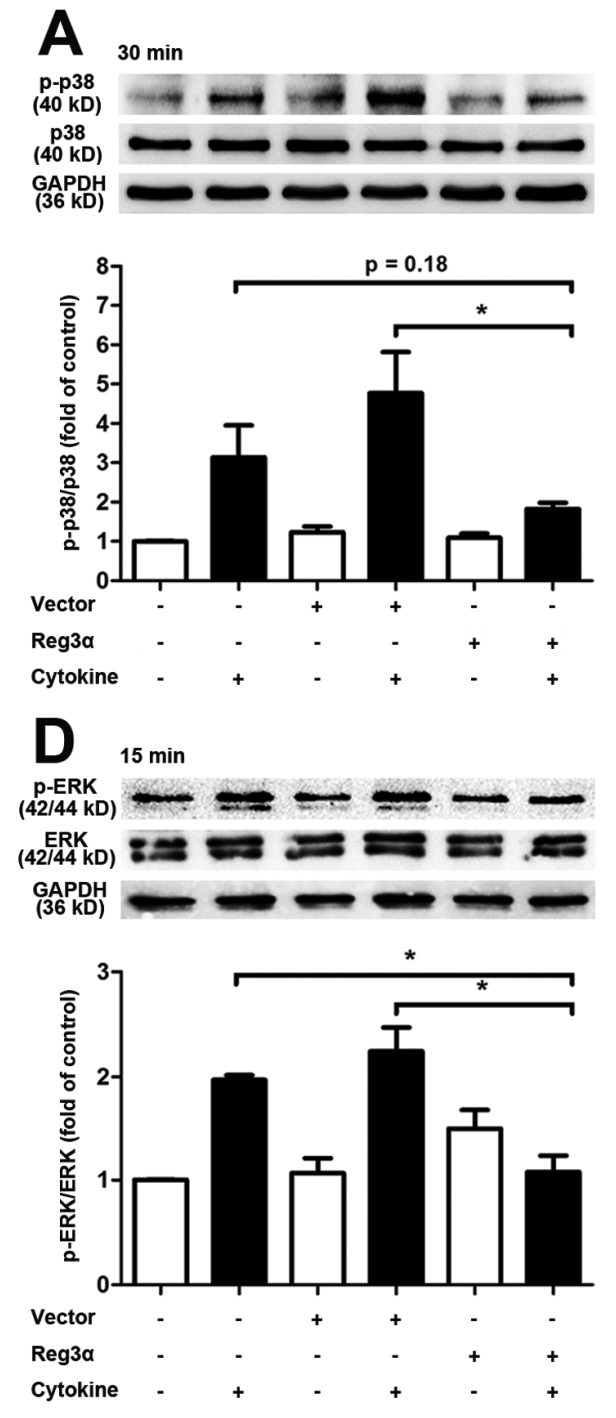
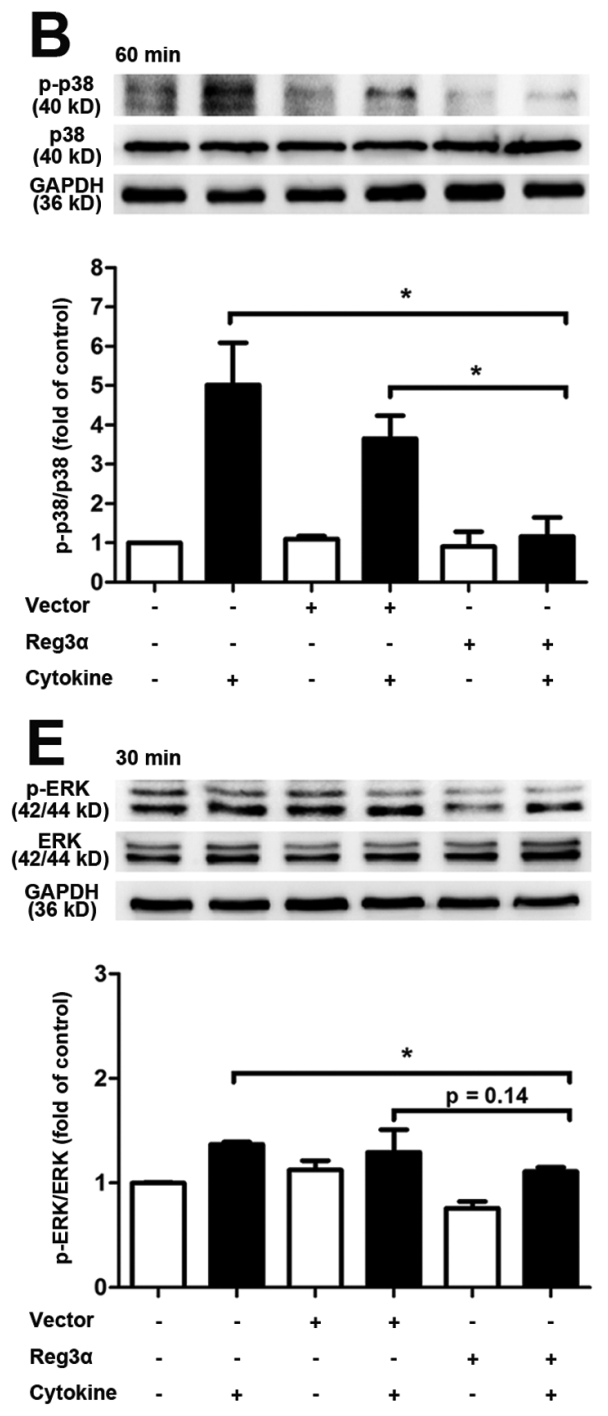
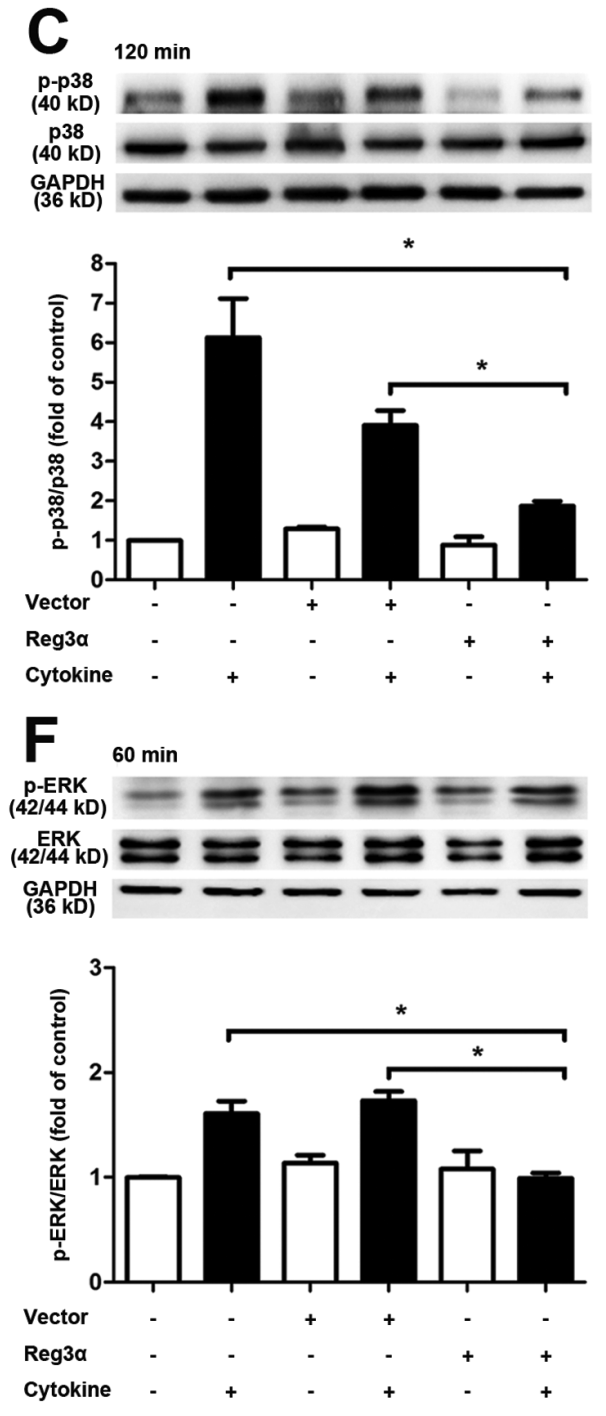

Figure 6. Reg3 $\alpha$ overexpression suppressed cytokine-induced activation of p38 MAPK and ERK but not JNK phosphorylation. Vector or Reg3 $\alpha$-transfected cells and normal cultured cells were incubated in the presence/absence of the inflammatory cytokine cocktail from 0-120 min. The phosphorylation of p38 and ERK were detected by Western blotting. (A-C) A time course of p38 phosphorylation was indicated by Western blotting and adjusted for total p38 MAPK. The phosphorylated ratio of p38 MAPK adjusted for normal cultured group also was shown in different treated groups. (D-F) A time course of ERK phosphorylation was indicated by Western blotting and adjusted for total ERK. The phosphorylated ratio of ERK adjusted for normal cultured group was also shown. GAPDH was used as a loading control. A representative blot was presented from at least three independent experiments. Values represent the means $\pm S E M, n=3$. ${ }^{*} P<0.05$ indicated significance.

of islet revascularization has been considered to determine the fraction of functional implanted islets (18). However, islet grafts with elevated $\operatorname{Reg} 3 \alpha$ production did not display a significantly higher content of intragraft endothelium than did the control group (Supplemental Figure 4), which means the beneficial effect of Reg $3 \alpha$ on improving islet transplantation is likely due to a combined action of antiapoptosis and pro-proliferation, but not pro-angiogenic activities.

Molecular mechanisms mediating the biological effect of Reg $3 \alpha$ seemed varying in different cell types and physiological circumstances $(9,11,35,36)$. Activation of cytokine-induced MAPKs plays a crucial role in controlling multiple gene regulatory networks, including the expression of pro- and antiapoptotic genes and tran- scription factors responsible for $\beta$-cell differentiation and insulin biosynthesis that fundamentally contribute to $\beta$-cell death $(37,38)$. Larsen, et al. found that ERK activation was required for cytokine-induced expression of iNOS (38) which plays an important role in oxidative stress-induced $\beta$-cell death. Meanwhile, the execution of cell death was highly related to the activation of MAPKs via triggering of ER stress 
and by the release of mitochondrial death signals (38). In this research, we found that $\operatorname{Reg} 3 \alpha$ overexpression abrogated cytokine-induced activation of ERK and p38 in INS- 1 cells, thereby protecting $\beta$-cell viability and function. These data are consistent with earlier findings that pharmacological inhibition of MAPKs could diminish cytokine-induced $\beta$-cell apoptosis $(37,39-41)$. Furthermore, Pdx-1 and MafA were already known as conserved transcriptional activators that regulate $\beta$-cell survival and insulin gene expression $(42,43)$, we proved that Reg $3 \alpha$ overexpression upregulated the protein level of both. We also proved that Reg $3 \alpha$ production upregulated the expression of antiapoptotic protein $\mathrm{Bcl}-2$ and downregulated the expression of cell death executor caspase-3 in the presence of cytokines. These data are in line with the upregulation of PCNA and p27Kip1, two indicators of cell proliferation and DNA replication $(44,45)$, and suggest that $\operatorname{Reg} 3 \alpha$ overexpression influences the fate of $\beta$ cells undergoing cytokine-induced apoptosis. We also investigated the possible effect of Reg $3 \alpha$ overexpression on ROS generation. It was found that Reg $3 \alpha$ overexpression could reduce cytokine-induced ROS generation in INS-1 pancreatic $\beta$ cells (Supplemental Figure 5), suggesting that not only an antiinflammatory but also an antioxidative mechanism could be involved in the cytoprotective effect of Reg $3 \alpha$ on pancreatic $\beta$ cells. Hence we used mechanistic researches to document the inhibition of inflammatory cytokines' damage and ROS generation via MAPKs pathway in vitro by Reg $3 \alpha$. One intriguing speculation is that $\operatorname{Reg} 3 \alpha$ production might be an intermediator involved in regulating the cytokine-activated signal molecules, partially through inhibit of the downstream kinases that have been implicated in both the p38 MAPK and MAPKERK $1 / 2$ signaling pathways, therefore affecting the common final pathway for $\beta$-cell failure. However, without cytokineinduced activation of MAPKs, Reg $3 \alpha$ production also exerts its effect on $\beta$ cells under normal conditions. This suggests that $\operatorname{Reg} 3 \alpha$ activates other molecules, by- passing MAPKs, to mediate $\beta$-cell proliferation and function. Recent studies have shown that Reg3 $\alpha$ activates PI3K-Akt signaling pathway to regulate cell proliferation and/or differentiation $(11,34,35)$. Further study is needed to prove whether other signaling pathways are correlated with Reg $3 \alpha$ response to $\beta$-cell survival.

As early graft damage was induced by multiple processes (46), we admit that Reg $3 \alpha$ could have other effects that potentially contribute to graft survival. Inflammatory cytokines have been verified to upregulate several chemokines in islets, directing lymphocytes and macrophage infiltration toward the site of transplantation. This effect can trigger local inflammation in islet grafts, which exacerbates $\beta$-cell damage and leads to a negative clinical outcome (47). Since previous studies represented an antiinflammatory role of Reg3 $\alpha$ in inflammatory bowel disease (IBD) and skin inflammation $(11,48,49)$, studies are needed to address whether $\operatorname{Reg} 3 \alpha$ production led to inhibition of chemokine expression in cultured islets and suppression of local inflammation in islet grafts of diabetic mice. Although the exostosin-like glycosyltransferase 3 (EXTL3) has been strongly suggested to be a receptor of Reg family protein to mediate Reg signaling for islet regeneration and it has been demonstrated that human $\operatorname{Reg} 3 \alpha$ depends on EXTL3 to mitigate skin injury $(11,33,50)$, further investigation is under way to confirm specific receptors on pancreatic $\beta$ cells, including downstream mediators and other interacting proteins that were poorly explored. Previous reports displayed that pancreatic islet-specific overexpression of Reg3 $\beta$ protein protected mice against streptozotocin-induced diabetes (51). To refine our investigation, we would like to ask whether transgenic overexpression of Reg $3 \alpha$ in islets can stimulate islet cell regeneration and/or shield the islets from experimental damage.

\section{CONCLUSION}

In conclusion, our present study is of significance, as we elucidate that $\operatorname{Reg} 3 \alpha$ protein exhibits cytoprotective properties on islet survival and function, contributing to better preservation of functional islet mass and euglycemia in marginal mass islet infusions. Our findings implicate the potential of $\operatorname{Reg} 3 \alpha$ to improve transplant outcomes, thereby reducing the number of donor islets and sustaining long-term function. The identification of Reg $3 \alpha$ function provides insights into mechanisms associated with early graft loss, which may ultimately lead to the identification of opportunities to control the local environment of transplanted islets as well as to the achievement of prolonged insulin independence.

\section{ACKNOWLEDGMENTS}

We thank JL Liu from McGill University Health Centre for the kind gift of plasmid pcDNA3.1-Reg3 $\alpha$. Also we would like to thank YB Ge from Nanjing Medical University and P Sun from Shanghai Institute of Materia Medica for excellent technical assistance with histology and islet isolation. We are grateful to X Han, XR Wang and $H$ Zhou from Nanjing Medical University for helpful discussion and valuable advice during the development of the study. This research was supported by the grants from National Basic Research Program of China (2011CB504000, 973 Program), the National Natural Science Foundation of China (81070656, 81170252, 81170715), the Open Research Project of Shanghai Key Laboratory of Diabetes Mellitus (SHKLD-KF-1102) and the Distinguished Medical Experts Program of Jiangsu Province, China.

\section{DISCLOSURE}

The authors declare that they have no competing interests as defined by Molecular Medicine, or other interests that might be perceived to influence the results and discussion reported in this paper.

\section{REFERENCES}

1. Shapiro AM, et al. (2000) Islet transplantation in seven patients with type 1 diabetes mellitus using a glucocorticoid-free immunosuppressive regimen. N. Engl. J. Med. 343:230-8.

2. Bennet W, et al. (1999) Incompatibility between human blood and isolated islets of Langerhans: a 
finding with implications for clinical intraportal islet transplantation? Diabetes. 48:1907-14.

3. Zhang N, et al. (2004) Elevated vascular endothelial growth factor production in islets improves islet graft vascularization. Diabetes. 53:963-70.

4. Bennet W, Groth CG, Larsson R, Nilsson B, Korsgren O. (2000) Isolated human islets trigger an instant blood mediated inflammatory reaction: implications for intraportal islet transplantation as a treatment for patients with type 1 diabetes. Ups. J. Med. Sci. 105:125-33.

5. Contreras JL, et al. (2004) Activated protein C preserves functional islet mass after intraportal transplantation: a novel link between endothelial cell activation, thrombosis, inflammation, and islet cell death. Diabetes. 53:2804-14.

6. Amrani A, Verdaguer J, Thiessen S, Bou S, Santamaria P. (2000) IL-1alpha, IL-1beta, and IFNgamma mark beta cells for Fas-dependent destruction by diabetogenic CD4(+) T lymphocytes. J. Clin. Invest. 105:459-68.

7. Keim V, Rohr G, Stockert HG, Haberich FJ. (1984) An additional secretory protein in the rat pancreas. Digestion. 29:242-9.

8. Fleming A, Rosenberg L. (2007) Prospects and challenges for islet regeneration as a treatment for diabetes: a review of islet neogenesis associated protein. J. Diabetes Sci. Technol. 1:231-44.

9. Cavard C, et al. (2006) Overexpression of regenerating islet-derived 1 alpha and 3 alpha genes in human primary liver tumors with beta-catenin mutations. Oncogene. 25:599-608.

10. Viterbo D, et al. (2008) Pancreatitis-associated protein 2 modulates inflammatory responses in macrophages. J. Immunol. 181:1948-58.

11. Lai Y, et al. (2012) The antimicrobial protein REG3A regulates keratinocyte proliferation and differentiation after skin injury. Immunity. 37:74-84.

12. Wang $Y$, et al. (2011) Coordinated age-dependent and pancreatic-specific expression of mouse Reg2Reg3alpha, and Reg3beta genes. Growth Factors. 29:72-81.

13. Taylor-Fishwick DA, Bowman A, KorngiebelRosique M, Vinik AI. (2008) Pancreatic islet immunoreactivity to the Reg protein INGAP. J. Histochem. Cytochem. 56:183-91.

14. Malka D, et al. (2000) Tumor necrosis factor alpha triggers antiapoptotic mechanisms in rat pancreatic cells through pancreatitis-associated protein I activation. Gastroenterology. 119:816-28.

15. Norkina O, Graf R, Appenzeller P, De Lisle RC. (2006) Caerulein-induced acute pancreatitis in mice that constitutively overexpress Reg/PAP genes. BMC Gastroenterol. 6:16.

16. Marselli L, et al. (2010) Gene expression profiles of Beta-cell enriched tissue obtained by laser capture microdissection from subjects with type 2 diabetes. PLoS One. 5:e11499.

17. Xue Y, et al. (2010) Study on pancreatic islet adaptation and gene expression during pregnancy in rats. Endocrine. 37:83-97.

18. Su D, et al. (2007) Angiopoietin-1 production in islets improves islet engraftment and protects islets from cytokine-induced apoptosis. Diabetes. 56:2274-83.
19. Committee for the Update of the Guide for the Care and Use of Laboratory Animals, Institute for Laboratory Animal Research, Division on Earth and Life Studies, National Research Council of the National Academies. (2011) Guide for the Care and Use of Laboratory Animals. 8th edition. Washington (DC): National Academies Press.

20. Zhang N, et al. (2006) Sirolimus is associated with reduced islet engraftment and impaired beta-cell function. Diabetes. 55:2429-36.

21. Chen L, et al. (2012) Diverse mechanisms of antidiabetic effects of the different procyanidin oligomer types of two different cinnamon species on $\mathrm{db} / \mathrm{db}$ mice. J. Agric. Food Chem. 60:9144-50.

22. Guo J, et al. (2010) Blockage of ceramide metabolism exacerbates palmitate inhibition of pro-insulin gene expression in pancreatic beta-cells. Mol. Cell Biochem. 338:283-90.

23. Meng ZX, et al. (2009) Activation of liver X receptors inhibits pancreatic islet beta cell proliferation through cell cycle arrest. Diabetologia. 52:125-35.

24. Yin X, et al. (2013) Hydroxycamptothecin induces apoptosis of human tenon's capsule fibroblasts by activating the PERK signaling pathway. Invest. Ophthalmol. Vis. Sci. 54:4749-58.

25. Wang T, et al. (2014) Cinnamtannin D-1 Protects Pancreatic beta-cells from palmitic acid-induced apoptosis by attenuating oxidative stress. J. Agric. Food Chem. 62:5038-45.

26. Chen F, et al. (2011) Dynamic regulation of PDX-1 and FoxO1 expression by FoxA2 in dexamethasone-induced pancreatic beta-cells dysfunction. Endocrinology. 152:1779-88.

27. Gurr W, et al. (2002) A Reg family protein is overexpressed in islets from a patient with new-onset type 1 diabetes and acts as T-cell autoantigen in NOD mice. Diabetes. 51:339-46.

28. Gurr W, Shaw M, Li Y, Sherwin R. (2007) RegII is a beta-cell protein and autoantigen in diabetes of NOD mice. Diabetes. 56:34-40.

29. Fetaud-Lapierre V, et al. (2013) Time-course proteomic analysis of taurocholate-induced necrotizing acute pancreatitis. J. Proteomics. 85:12-27.

30. Coffey R, Nam H, Knutson MD. (2014) Microarray analysis of rat pancreas reveals altered expression of alox 15 and regenerating islet-derived genes in response to iron deficiency and overload. PLoS One. 9:e86019.

31. Boker A, et al. (2001) Human islet transplantation: update. World J. Surg. 25:481-6.

32. Udayasankar J, et al. (2009) Amyloid formation results in recurrence of hyperglycaemia following transplantation of human IAPP transgenic mouse islets. Diabetologia. 52:145-53.

33. Rink JS, Chen X, Zhang X, Kaufman DB. (2012) Conditional and specific inhibition of NF-kappaB in mouse pancreatic beta cells prevents cytokineinduced deleterious effects and improves islet survival posttransplant. Surgery. 151:330-9.

34. Levetan CS, et al. (2008) Discovery of a human peptide sequence signaling islet neogenesis. Endocr. Pract. 14:1075-83.

35. Cui W, et al. (2009) Overexpression of Reg3alpha increases cell growth and the levels of cyclin D1 and CDK4 in insulinoma cells. Growth Factors. 27:195-202.

36. Koblas T, et al. (2012) Activation of the Jak/Stat signalling pathway by leukaemia inhibitory factor stimulates trans-differentiation of human non-endocrine pancreatic cells into insulin-producing cells. Folia Biol. (Praha). 58:98-105.

37. Eizirik DL, Mandrup-Poulsen T. (2001) A choice of death - the signal-transduction of immune-mediated beta-cell apoptosis. Diabetologia. 44:2115-33.

38. Cnop M, et al. (2005) Mechanisms of pancreatic beta-cell death in type 1 and type 2 diabetes: many differences, few similarities. Diabetes. 54 Suppl 2:S97-107.

39. Larsen CM, et al. (1998) Interleukin-1beta-induced rat pancreatic islet nitric oxide synthesis requires both the p38 and extracellular signalregulated kinase 1/2 mitogen-activated protein kinases. J. Biol. Chem. 273:15294-300.

40. Maedler K, et al. (2004) Glucose- and interleukin1beta-induced beta-cell apoptosis requires $\mathrm{Ca} 2+$ influx and extracellular signal-regulated kinase (ERK) $1 / 2$ activation and is prevented by a sulfonylurea receptor 1 /inwardly rectifying $\mathrm{K}+$ channel 6.2 (SUR/Kir6.2) selective potassium channel opener in human islets. Diabetes. 53:1706-13.

41. Zhuang S, Schnellmann RG. (2006) A deathpromoting role for extracellular signal-regulated kinase. J. Pharmacol. Exp. Ther. 319:991-7.

42. Aramata S, Han SI, Kataoka K. (2007) Roles and regulation of transcription factor MafA in islet beta-cells. Endocr. J. 54:659-66.

43. Miyatsuka T, Matsuoka TA, Kaneto H. (2008) Transcription factors as therapeutic targets for diabetes. Expert Opin. Ther. Targets. 12:1431-42.

44. Georgia S, Bhushan A. (2006) p27 regulates the transition of beta-cells from quiescence to proliferation. Diabetes. 55:2950-2956.

45. Rachdi L, et al. (2006) Differential effects of p27 in regulation of beta-cell mass during development, neonatal period, and adult life. Diabetes. 55:3520-8.

46. Gibly RF, et al. (2011) Advancing islet transplantation: from engraftment to the immune response. Diabetologia. 54:2494-505.

47. SoRelle JA, et al. (2013) Withaferin A inhibits proinflammatory cytokine-induced damage to islets in culture and following transplantation. Diabetologia. 56:814-24.

48. Gironella M, et al. (2005) Anti-inflammatory effects of pancreatitis associated protein in inflammatory bowel disease. Gut. 54:1244-53.

49. van Beelen Granlund A, et al. (2013) REG gene expression in inflamed and healthy colon mucosa explored by in situ hybridisation. Cell Tissue Res. 352:639-46.

50. Kobayashi S, et al. (2000) Identification of a receptor for reg (regenerating gene) protein, a pancreatic beta-cell regeneration factor. J. Biol. Chem. 275:10723-6.

51. Xiong X, et al. (2011) Pancreatic islet-specific overexpression of Reg3beta protein induced the expression of pro-islet genes and protected the mice against streptozotocin-induced diabetes mellitus. Am. J. Physiol. Endocrinol. Metab. 300:E669-80. 